Project ID number: 60326

\title{
Project Title: $\quad$ Isolation of Metals from Liquid Wastes: Reactive Scavenging by Sorbents in Turbulent Reactors
}

$\begin{array}{ll}\text { Publication Date: Wednesday, March 08, } 2000 & \\ \text { Lead Investigator: } & \\ \text { Jost O.L. Wendt } & \\ \text { Department of Chemical and Environmental Engineering } & \\ \text { The University of Arizona } & \\ \text { Tucson, AZ 85721 } & \\ \begin{array}{l}\text { (520) 621-2591 } \\ \text { wendt@u.arizona.edu }\end{array} & \\ \text { Co-Investigators: } & \text { Arne J. Pearlstein } \\ \text { Alan R. Kerstein } & \text { Department of Mechanical and Industrial } \\ \begin{array}{l}\text { DOE Combustion Research Facility } \\ \text { Sandia National Laboratory }\end{array} & \text { Engineering } \\ \begin{array}{l}\text { Livermore, CA 94551 } \\ \text { (510) 294-2390 }\end{array} & \text { University of Illinois at Urbana-Champaign } \\ \text { kerstein@ california.sandia.gov } & \text { Urbana, IL 61801 } \\ & \text { (217) 333-3658 } \\ \text { William P. Linak } & \text { ajp@ uiuc.edu } \\ \text { Air Pollution Technology Branch } & \\ \text { National Risk Management Research Laboratory } & \text { Alexander Scheeline } \\ \text { US Environmental Protection Agency } & \text { Department of Chemistry } \\ \begin{array}{l}\text { Research Triangle Park, NC 27711 } \\ \text { (919) 541-5792 }\end{array} & \text { University of Illinois at Urbana-Champaign } \\ \text { linak.bill@epa.gov } & \text { Urbana, IL 61801 } \\ \end{array}$

\section{Number of graduate students actively invol ved in project: 4}

\section{Research Objective:}

The objective of this work is to develop the fundamental knowledge base for the design of a broad class of hightemperature reactive capture processes to treat metals-bearing liquid waste in the DOE inventory. The major thrust is devoted to understanding phenomena that govern process performance and are critical to achieving emission specifications.

\section{Research Progress and Implications:}

In the incineration of liquid hazardous wastes, there exist "rogue" droplets (>100 mm radius) which penetrate past the flame zone and burn as isolated droplets in the postflame gasses. Mulholland et al. [Combust. Flame, 86: 297310 (1991)] demonstrated that these droplets can limit the overall incineration efficiency. Hence detailed knowledge of the droplet lifetimes are essential to keeping the destruction removal efficiency in excess of the $99.99 \%$ required for these wastes. The spread in trajectory endpoints of individual evaporating droplet streams of a fuel mixture injected into a hot swirling gas turbulent diffusion flame was investigated numerically. Preliminary results indicate good agreement with the measurements reported by Mulholland et al. Correlations between endpoints and initial droplet size, initial droplet velocity, inter-droplet spacing, and droplet injection angle were investigated. The model utilizes the novel One Dimensional Turbulence (ODT) model developed by Kerstein for the time developing fluid velocity and temperature fields.

The One Dimensional Turbulence Model is able to sufficiently predict the mean velocity and temperature profiles of the Mulholland et al. combuster. The ODT model can accurately predict the spread of droplet burnout points due to the random variation of the velocity/temperature field due to the high turbulence in hazardous waste incineration without the cost of doing a 3-dimensional (DNS) calculation. The ODT model also reasonably reproduces the data for the effects due to injection angle. The ODT model somewhat reproduced the spread for variations in the initial velocity. (Incorrect initial conditions are the most likely cause of the discrepancy with the highest velocity case.) The ODT model did not reproduce the spacing/diameter variations which are recorded in Mulholland et. al. (Again, incorrect initial conditions are suspected to be the cause of the failure.) 
Currently, critical assumptions are made in the ODT model concerning the behavior of droplets in flow systems. To better predict the behavior of droplet, models have been modified and constructed (originally developed for liquid drops moving through an immiscible liquid) to better deal with the large density ratios characteristic of liquid drops moving through a gas. Results to date show that the drop shapes computed for high-density ratios can be very different from those encountered at low speed, with considerable elongation in the flow direction occurring. We also find that there is a range of conditions (density ratio, surface tension, drop size, drop velocity) for which more than one drop shape can occur. (This result may explain the bimodal axis ratio distribution observed for a certain drop-size range in size-classified raindrops, with implicationsfor scavenging of trace gases and particulate from the atmosphere.) Further code modification to account for heat and mass transfer is proceeding apace.

To extend and verify the ODT model, experiments are planned to measure the movement and destruction of droplets in turbulent flows. Measurement of droplet trajectories in reactive flows requires novel optical apparatus, which has taken considerable ingenuity to design, fabricate, assemble, and test. The apparatus, designed at the University of Illinois, has now been assembled at the University of Arizona, with optical alignment proceeding. Check-points along the way have included final design of the optical train with theoretical spatial resolution of 11 microns (RMS) (June, 1999), hiring of a post-doctoral fellow to perform the experimental work (September, 1999), completion of fabrication of precision mounting hardware and shipment to Arizona (January, 2000), and commencement of on-site work with the post-doctoral fellow's arrival (January, 2000). The reactor was subsequently upgraded to make optical access more convenient, and optical safeguards in excess of those required by regulation (but judged to be necessary and prudent) added to the optical train to insure against leakage of ultraviolet laser light. We will start obtaining results in May.

Lastly, screening tests have been completed to examine the use of high temperature sorbents to reactively capture strontium and cesium. Cesium alone vaporizes readily in the flame, and subsequently nucleates in the sampling probe to form sub-micron particles. Cesium is almost completely captured in the presence of kaolinite. It is not captured by lime. Chlorine raises the dewpoint of cesium. This is unusual, in that chlorine tends to lower the dewpoint of most metals. The presence of chlorine does appear to have some effect on the reactive capture of cesium by kaolinite. It does not appear to affect the capture of cesium by lime. The presence of sulfur also raises the dewpoint of cesium. However, this appears to have little effect on the capture by kaolinite. It does enhance the capture of cesium by lime. This is probably due to the speciation of the cesium compounds. Strontium alone does not vaporize in the flame, and is only minimally captured on kaolinite and lime, probably by physical coagulation processes and not reactive scavenging. The presence of chlorine enhances the vaporization of strontium and subsequent capture by kaolinite. However, this vaporization does not promote capture on lime. In contrast to the equilibrium predictions, sulfur appears to enhance the volatilization of strontium. However, this process does not appear to aid in strontium capture.

\section{Planned Activities:}

Under the current project, experiments will continue at the University of Arizona to validate the droplet model(s) against laminar flow reactor experiments. The laser diagnostic apparatus will be moved to US EPA where a turbulent flow reactor will be used to examine droplet destruction.

\section{Information Access:}

Davis, S.B., Amos, J.M., Gale, T.K., Wendt, J.O.L., Biermann, J.J.B. and Voogt, N., "Use of Sorbents from Paper recycling Wastes for the High Temperature Capture of Multiple Metals in the Presence of Chlorine" presented at $4^{\text {th }}$ International Syposium \& Exhibition on Gas Cleaning at High Temperatures, University of Karlsruhe (TH),Sep 22-24, 1999.

Amos, J.M. and J.O.L.Wendt, "High Temperature Scavenging of Cesium and Strontium by Sorbents", Poster presented at Joint Meeting of the US Sections of the Combustion Institute, George Washington University, Washington, DC March 1999

Schmidt J.R., Kerstein, A.R., and J.O.L. Wendt, "Trajectories of Evaporating Droplets in Highly Turbulent Flows using the One Dimensional Turbulence Model" presented at the Fall Meeting of the Western States Section of the Combustion Institute, Colorado Springs, Colorado, March 13-14, 2000, to be submitted for publication in Combust. Flame

Amos J.M., Davis, S.B., and J.O.L. Wendt, "Evaluation of Sorbent to Reduce Radionuclide Emissions from Mixed Waste Incineration", to be submitted for publication to Environ. Sci, and Technol., March 2000 